\title{
Distinction of Human Immunodeficiency Virus Type 1 Neutralization and Infection Enhancement by Human Monoclonal Antibodies to Glycoprotein 120
}

Akira Takeda,* James E. Robinson, David D. Ho, Christine Debouck, Nancy L. Haigwood, and Francis A. Ennis* *Division of Infectious Diseases, Department of Medicine, University of Massachusetts Medical School, Worcester, Massachusetts 01655 ; Department of Pediatrics and Microbiology, Immunology and Parasitology, Louisiana State University School of Medicine, New Orleans, Louisiana 70112; Division of Infectious Diseases, The Aaron Diamond AIDS Research Center, New York University School of Medicine, New York 10016; Department of Molecular Genetics, Smith Kline Beecham Pharmaceuticals, King of Prussia, Pennsylvania 19479; and Chiron Corporation, Emeryville, California 94608

\begin{abstract}
There is increasing evidence that sera from HIV-1-infected individuals contain antibodies that enhance infection by HIV-1 in vitro. Previous work has demonstrated that complement receptors on $T$ lymphoid cells and Fc receptors for IgG (Fc $\gamma R)$ on monocytic cells are required for enhanced infection by antibody-complexed HIV-1. Characterization of such infection-enhancing antibodies is essential because immunogenic epitopes which induce enhancing antibodies should be excluded from HIV-1 vaccines. This study was conducted to identify enhancing antibodies involved in Fc R-mediated enhancement of HIV1 infection employing IgG human monoclonal antibodies (HMAbs) reactive against gp1 20 of HIV-1, which were produced by $B$ cell lines derived from an HIV-1-infected individual. A potent neutralizing HMAb N70-1.5e did not enhance infection by HIV-1 (IIIB and MN strains), whereas HMAb N70-2.3a mediated enhancement of HIV-1 infection, but had little neutralizing activity. A competition radio immunoassay demonstrated that the two antibodies bind to distinct epitopes. These results indicated that enhancing and neutralizing antibodies can be induced by different epitopes on gp120, suggesting the potential for development of safe vaccines against HIV-1 by exclusion of immunogenic epitopes for enhancing antibodies. We made attempts to identify the epitope on gp120 that is recognized by the enhancing antibody N70-2.3a by using recombinant HIV-1 proteins and found that the antibody binds to a conformational site of nonvariable sequences in the carboxyl half (aa 272-509) of gp120. (J. Clin. Invest. 1992. 89:19521957.) Key words: HIV-1 • infection enhancement • neutralization • monoclonal antibodies $\bullet$ epitope
\end{abstract}

\section{Introduction}

Enhancement of HIV-1 infection by specific antibodies has been described in vitro (1-6). This raises a major concern in

Address correspondence and reprint requests to Dr. Francis A. Ennis, Division of Infectious Diseases and Immunology, Department of Medicine, University of Massachusetts Medical School, Worcester, MA 01655.

992.

1. Abbreviations used in this paper: FBS, fetal bovine serum; FcR, Fc receptor; HMAb, human monoclonal antibodies; HTLV, human T cell lymphotrophic virus.

J. Clin. Invest.

(c) The American Society for Clinical Investigation, Inc. $0021-9738 / 92 / 06 / 1952 / 06 \$ 2.00$

Volume 89, June 1992, 1952-1957 reference to HIV vaccine development, since very low concentrations of anti-HIV-1 antibodies can enhance HIV-1 infection. Robinson et al. first reported complement-mediated enhancement of HIV-1 infection in a T cell line bearing complement receptors (1). We have previously demonstrated antibody-dependent enhancement of HIV-1 infection via Fc receptor $(\mathrm{FcR})^{1}$-mediated entry using a human monocytic cell line U937 that possesses FcRs for IgG (3). Heat-inactivated sera from HIV-1 antibody-positive individuals enhanced infection of U937 cells. This enhancement was blocked by the presence of heat-aggregated -globulin, a potent ligand for FcRs. The IgG fraction from an HIV-1 antibody-positive serum-enhanced HIV-1 infection at the same serum dilution equivalents. IgG-F $\left(\mathrm{ab}^{\prime}\right)_{2}$ failed to enhance HIV-1 infection, but still possessed neutralizing activity for HIV-1. We thus concluded that the enhancement of HIV-1 infection requires the Fc portion of IgG and is mediated by Fc Rs. We examined several HIV-1 antibody positive sera, and enhancement of infection was generally detected at higher dilutions of the sera. The enhancement at subneutralizing concentrations raised a question: are enhancing antibodies and neutralizing antibodies different categories of antibodies, or are these activities concentration-dependent phenomena due to the same antibodies? To address this question, we examined the reactivity of the sera on Western blots to antigens of HIV-1 (human T cell lymphotrophic virus-IIIB strain [HTLV-IIIB]) to determine whether enhancing sera react with specific viral antigens; however, there were no specific differences in terms of major viral proteins between enhancing sera and nonenhancing sera (data not shown).

Therefore, we have attempted to approach this issue by using rabbit antisera raised against the amino- and the carboxyl-terminal halves of HIV-1 gp120, and human monoclonal antibodies (HMAbs) directed against gp120, which were derived from HIV-1-infected donor peripheral blood lymphocytes.

\section{Methods}

Viruses. HTLV-IIIB, a prototype HIV-1 strain (7) and HTLV-IIIMN (7) were obtained from the AIDS Research and Reference Reagent Program. These strains were grown in H9 cells as acutely infected cultures. A local strain, HIV-1 J62 (8), that was isolated from the peripheral blood mononuclear cells of an HIV-1-infected patient by cocultivation with mitogen-stimulated $T$ cells from seronegative blood, was used to prepare native gp 120 antigen for binding assays.

Rabbit antisera raised against recombinant HIV-1 envelope constructs. Recombinant protein Kp120NN corresponding to the aminoterminal moiety of gp1 20 (aa 12-257) was obtained by expression of a 738-bp Asp718I-PvulI filled-in restriction gp120 gene fragment inserted in the pOTSKF33 bacterial vector (9). Recombinant protein Kp120C corresponding to the carboxyl-terminal half of gp 120 (aa 258- 
437) was obtained by expression of a 539-bp PvulI-HindIII filled-in restriction fragment, in which an oligonucleotide containing translation stop codons in all three frames was inserted at the BglII site at the end of gp 120. The gene fragments were isolated from the BH10 clone of HIV-1 (10). Polyclonal antibodies were obtained from rabbits that were hyperimmunized with those constructs. The reactivity of those rabbit sera with each construct was tested by ELISA.

Human monoclonal antibodies to HIV-1 gp120. IgG HMAbs with specificity for HIV-1 gp 120 were produced by EBV-transformed B cells established from peripheral blood of asymptomatic HIV-1-infected subjects, as described previously (11). We used two HMAbs, designated $\mathrm{N} 70-1.5 \mathrm{e}$ and $\mathrm{N} 70-2.3 \mathrm{a}$, that are derived from the same donor and bind to HTLV-IIIB. N70-1.5e identifies a relatively conserved conformational epitope on gp120 that is glycosylation dependent, and is involved in binding of gp 120 to CD4. This antibody has potent neutralizing activity against a variety of laboratory and primary strains of HIV-1 (12). N70-2.3a reacts with a well-conserved epitope on gp120, and its poor reactivity with reduced $\mathrm{gp} 120$ suggested it recognized a conformation-dependent epitope (11). Both are of the IgGI subclass and are directed against relatively conserved epitopes of gp120. N70-2.3a has reacted with all 12 strains tested, including HTLV-IIIB and HTLVIIIRF, and N70-1.5e reacts with a majority of strains but not with RF. Another HMAb, N70-1.9b, which recognizes a linear epitope within the $\mathrm{V} 3$ region of $\mathrm{MN}$ and $\mathrm{J} 62$, and does not bind to virus strains that lack the $\mathrm{V} 3$ region of $\mathrm{MN}$ (13), was also 13 used for binding assays to determine relative affinities of N70-1.5e and N70-2.3a.

HIV-1 infection enhancement assay in U937 cells. The assay for the detection of enhancement of HIV-1 infection was performed with HTLV-IIIB, using a slightly modified method from that which we described previously (3). Cell-free HIV-1 (HTLV-IIIB strain) harvested from an acutely infected $\mathrm{H} 9$ culture and titrated on $\mathrm{C} 8166$ cells was used as the virus inoculum. In a part of the experiments we also used an HIV-1 strain HTLV-IIIMN. Briefly, an HIV-1 inoculum (0.1 $\mathrm{ml}$ ) containing $5 \times 10^{3} 50 \%$ tissue culture infective dose $\left(\mathrm{TCID}_{50}\right)$ in RPMI 1640 medium supplemented with 2\% fetal bovine serum (FBS) (GIBCO Laboratories, Grand Island, NY) was mixed with a 0.9-ml portion of heat-inactivated $\left(56^{\circ} \mathrm{C}\right.$ for $\left.30 \mathrm{~min}\right)$ rabbit antiserum, or a monoclonal antibody that was serially diluted tenfold from $10^{-1}$ to $10^{-7}$ in RPMI 1640 medium, and then incubated for $30 \mathrm{~min}$ at $4^{\circ} \mathrm{C}$. These virus-antibody mixtures were then incubated for $1 \mathrm{~h}$ at $37^{\circ} \mathrm{C}$ with $5 \times 10^{5}$ U937 cells (American Type Tissue Collection, Rockville, MD). The infected U937 cells were washed three times and resuspended at $2 \times 10^{5}$ cells $/ \mathrm{ml}$ in RPMI 1640 medium supplemented with $10 \%$ FBS, $10 \mathrm{mM}$ Hepes buffer, $2 \mathrm{mM}$ L-glutamine, $100 \mathrm{U} / \mathrm{ml}$ of penicillin, and $100 \mu \mathrm{g} / \mathrm{ml}$ of streptomycin. Each of the $1-\mathrm{ml}$ cell suspensions was then cultured in 48-well multiculture plates (Costar Data Packaging, Cambridge, MA). On day 3, half of the culture medium in each well was replaced with fresh medium. On day 5 , the culture supernatants were harvested for determination of virus yields by p24 ELISA (DuPont Instruments, Wilmington, DE) (14). Each experiment was performed with duplicate cultures. Previously, we demonstrated that the enhanced infection measured by yields of $\mathrm{p} 24$ was confirmed by the percent cytoplasmic HIV-1 antigen-positive cells detected by an indirect immunofluorescence assay (3).

$H I V-1$ neutralization assay in $H 9$ cells. Neutralization assays were performed against HTLV-IIIB, as described previously (15). Each virus inoculum $\left(100 \mu \mathrm{l}, 50 \mathrm{TCID}_{50}\right)$ was preincubated with indicated amounts of antibodies at serial dilutions $(100 \mu \mathrm{l})$ for $1 \mathrm{~h}$ at $37^{\circ} \mathrm{C}$ before inoculation onto $2 \times 10^{6} \mathrm{H} 9$ cells in $5 \mathrm{ml}$ of RPMI 1640 medium supplemented with $20 \%$ FBS. On days 7-10, each of the culture supernatants was examined for p24 antigen. Neutralization was defined as $>90 \%$ reduction in supernatant p24 antigen, compared with control cultures.

Competition radioimmunoassay. Purified HIV-1 glycoproteins from the J62 strain were immobilized on small strips of nitrocellulose and blocked in BSA (11). $90 \mu \mathrm{g}$ of purified HMAb N70-2.3a was radioiodinated by Iodobeads (BioRad Laboratories, Richmond, CA), (lactoperoxidase) method. The radioactivity of the labeled HMAb was $\sim 115,000 \mathrm{cpm} / \mu \mathrm{g}$. Immobilized antigen or control nitrocellulose strips were incubated with $50 \mu \mathrm{g} / \mathrm{ml}$ of purified HMAb, N70-1.5e, N70-2.3a, or buffer for $1 \mathrm{~h}$, and then washed. Labeled HMAb N70-2.3a was added for $1 \mathrm{~h}$ and then the nitrocellulose strips were washed and counted for radioactivity.

Recombinant HIV-1 gp120 proteins. Nonglycosylated HIV-SF2 recombinant envelope polypeptides, designated as env-2-3 (full length protein, AA2b-510), env 1 ( $\mathrm{NH}_{2}$-terminal half, AA2b-376), env 4 (COOH-terminal half, AA272-509), and variants deleted in one to five hypervariable regions, were obtained by expression of gp 120 gene fragments inserted into the pHL15 yeast vector, as described previously (16). The gene fragments were derived from HIV-SF2 strains (17).

ELISA with envelope polypeptides. Recombinant gp120 proteins were absorbed to microtiter plates at $2 \mu \mathrm{g} / \mathrm{ml}$ in borate buffer. After plates were washed, biotinylated HMAb N70-2.3a that was diluted serially was added for $1 \mathrm{~h}$ and detected using streptavidin, streptavidin conjugated to horseradish peroxidase (HRP-streptavidin; Zymed Labs, Inc., San Francisco, CA). Wells were developed with 2,2'-amino-bis (3-ethyl-benzenethiozyline 6-sulfonic acid) (ABTS) (Sigma Chemical Co., St. Louis, MO).

Comparison of HMab binding affinities. To compare the relative affinities of $1.5 \mathrm{e}$ and 2.3a, we used an assay based in principle on the method of Friguet et al. (18), in which antibody is first incubated in solution with antigen and then the relative amount of unbound antibody is determined by indirect ELISA. For these experiments, both HMAbs were biotinylated as previously described (12), and used at an estimated final concentration of $8 \mathrm{ng} / \mathrm{ml}$. In the solution phase reaction, biotinylated antibodies were mixed with equal volumes of baculovirus expressed recombinant $\mathrm{gp} 120$ at final concentrations ranging from 0.25 to $4 \mu \mathrm{g} / \mathrm{ml}$. Controls consisted of biotinylated antibodies mixed with dilution buffer alone. After $2 \mathrm{~h}$ at room temperature, the antibody-antigen mixtures were incubated with solid-phase gp 120 and the amount of unbound biotin-HMab was measured by ELISA, using peroxidase-conjugated streptavidin as the detecting reagent and TMB$\mathrm{H}_{2} \mathrm{O}_{2}$ as chromogenic substrate.

In the ELISA, solid-phase antigen consisted of native gp 120 from the HIV-1 $1_{\text {J62 }}$ strain captured in 96-well Immulon II assay plates (Dynatech Laboratories, Chantilly, VA) coated for $1 \mathrm{~h}$ with $5 \mu \mathrm{g} / \mathrm{ml}$ of HMAb N70-1.9b. This antibody identifies a highly strain-restricted epitope within the V3 loop of strains J62 and HTLV-III $\mathrm{MN}_{\text {(13), and it does not }}$ compete with either $2.3 \mathrm{a}$ or $1.5 \mathrm{e}$. N70-1.9b was used as a capture reagent since it does not react with LAV gp1 20 (11), and hence, could not generate false signals by binding to soluble phase LAV gp120-HMAb complexes. The source of native $\mathrm{J} 62 \mathrm{gp} 120$ was detergent-treated cellfree culture fluid from a chronically infected continuous $T$ cell line. We also established in earlier studies that $2.3 \mathrm{a}$ and $1.5 \mathrm{e}$ showed equivalent reactivity with both LAV rgp 120 and native J62 gp 120 in an ELISA in which gp 120 was immobilized in Con A-coated wells (8).

Statistics. Data from infection enhancement assays were analyzed using quadratic assumption because the data fit a quadratic model with a $P$ value less than 0.05 . When the model was not significant, the analysis of variance with a Student-Newman-Keuls $t$ test was used.

\section{Results}

Localization of enhancing epitopes using rabbit antisera. Initial experiments were conducted to define whether the major glycoprotein gp 120 has functional site(s) that can elicit enhancing antibodies. It is known that this envelope protein contains major epitopes recognized by the humoral immune system. We tested heat-inactivated polyclonal rabbit antisera raised against recombinant proteins corresponding to the amino-terminal half or the carboxyl-terminal half of gp120 for infection-enhancing activity, and found that both of these polyclonal antisera showed inhibitory activity at high concentrations of sera, and enhanced infection at lower sera concentrations (Table I). 
Table I. HIV-1 Infection Enhancement Activity in Polyclonal Rabbit Antisera Raised Against Recombinant HIV-1 Envelope Contructs

\begin{tabular}{|c|c|c|c|}
\hline \multicolumn{2}{|c|}{ Serum dilution } & \multicolumn{2}{|c|}{$\mathrm{p} 24(\mathrm{ng} / \mathrm{ml}) \ddagger$} \\
\hline & & Rabbit antisera ${ }^{*}$ & Directed against \\
\hline & serum* & Kp120 C & Kp120 NN \\
\hline HIV alone & $30.75 \pm 2.75$ & $31.0 \pm 2.0(1.0)$ & $30.75 \pm 1.75(1.0)$ \\
\hline $10^{-1}$ & $11.75 \pm 1.25$ & $<1.0$ & $5.75 \pm 2.75$ \\
\hline $10^{-2}$ & $12.5 \pm 1.5$ & $5.25 \pm 1.75$ & $14.25 \pm 3.25$ \\
\hline $10^{-3}$ & $15.0 \pm 0.5$ & $21.0 \pm 0.5$ & $26.5 \pm 8.0$ \\
\hline $10^{-4}$ & $29.75 \pm 1.25$ & $38.0 \pm 4.5$ & $36.0 \pm 0.5$ \\
\hline $10^{-5}$ & $26.5 \pm 1.5$ & $43.75 \pm 6.25(1.41)$ & $48.75 \pm 7.25(1.59)$ \\
\hline $10^{-6}$ & $32.75 \pm 1.25$ & $44.0 \pm 2.0(1.42)$ & $33.75 \pm 2.25$ \\
\hline $10^{-7}$ & $29.5 \pm 2.5$ & $36.0 \pm 2.5$ & $29.0 \pm 5.0$ \\
\hline
\end{tabular}

* All rabbit sera were heat inactivated $\left(56^{\circ} \mathrm{C}\right.$ for $\left.30 \mathrm{~min}\right)$ before being tested. $\ddagger$ The results of one of two similar experiments are shown. $\mathrm{P} 24$ values are expressed as the mean $\pm \mathrm{SD}$ of duplicate cultures. The numbers in parentheses represent the enhancement indices compared with the control of HIV-1 alone.

Thus gp120 appears to contain epitopes that induce enhancing as well as neutralizing antibodies in both its amino- and carboxyl-terminal moieties, although it remains uncertain whether those epitopes are identical or distinct.

Neutralizing and enhancing activities of HMAbs. Thus, to explore the possibility that enhancing and neutralizing antibodies may be induced by distinct epitopes, we used HMAbs to gp 120, which were recently described (11). We used HMAbs N70-1.5e and N70-2.3a; both are of the IgG1 subclass and are directed against conserved epitopes on gp120. We tested for neutralizing activity of HTLV-IIIB infection of $\mathrm{H} 9$ cells, as shown in Fig. 1, $a$ and $b$. N70-2.3a exhibits weak, equivocal neutralizing activity against HTLV-IIIB in HIV-1 neutralization assays (15); neutralizing activity as defined as more than $90 \%$ inhibition was only observed at antibody concentrations of $10 \mu \mathrm{g} / \mathrm{ml}$. The other HMAb N70-1.5e showed potent neutral-

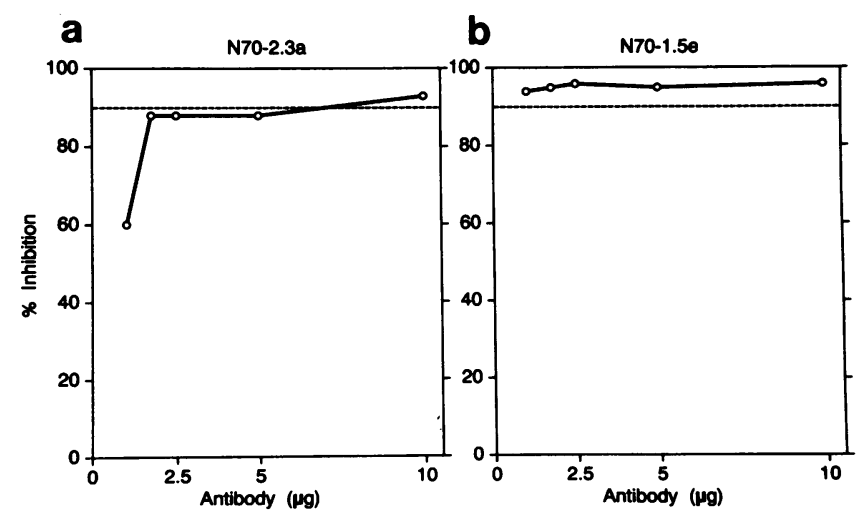

Figure 1. HIV-1-neutralizing activities of human monoclonal antibodies N70-2.3a $(a)$ and N70-1.5e $(b)$. Neutralization assays were performed against HTLV-IIIB, as described in Methods. Indicated amounts of antibodies $(100 \mu \mathrm{l})$ were preincubated with virus inoculum $\left(100 \mu \mathrm{l}, 50 \mathrm{TCID}_{50}\right)$ for $1 \mathrm{~h}$ at $37^{\circ} \mathrm{C}$ and then mixed with $2 \times 10^{6}$ H9 cells. On days 7 through 10 , each of the culture supernatants was examined for p24 antigen. Neutralization was defined as $>90 \%$ reduction in supernatant p24 antigen compared with control cultures. izing activity against HTLV IIIB, even at antibody concentrations as low as $1 \mu \mathrm{g} / \mathrm{ml}$.

On the other hand, assays for enhancement of infection showed reciprocal results (Fig. 2, $a$ and $b$ ). Infection enhancement assays were performed using a slightly modified method from that which we described previously (3). Enhancement of HIV-1 infection was observed with N70-2.3a, which enhanced HTLV IIIB infection at HMAb dilutions ranging from 13.4 $\mu \mathrm{g} / \mathrm{ml} \times 10^{-4}$ to $10^{-7}$, as compared with the absence of the antibody $(P<0.001)$. The peak enhancement index was 1.41 at dilution $10^{-7}$. In contrast, N70-1.5e failed to exhibit enhancement of infection even at concentrations as low as $730 \mu \mathrm{g} / \mathrm{ml}$ $\times 10^{-10}$. Instead, infection was significantly reduced by the presence of monoclonal antibody N70-1.5e at $730 \mu \mathrm{g} / \mathrm{ml} \times 10^{-1}$ through $10^{-3}$, as compared with the absence of $\operatorname{IgG}(P<0.05)$. These findings indicate that these enhancing and neutralizing antibodies are different populations of antibodies, and that this potent neutralizing antibody does not mediate infection enhancement. We also performed an infection enhancement assay with the MN strain of HIV-1, and an enhanced level of infection mediated by N70-2.3a was observed similar to the results with the IIIB strain (Fig. $2 c$ ), suggesting that the enhancing epitope detected by N70-2.3a is conserved on IIIB and MN. The neutralizing HMAb N70 1.5e neutralized $\mathrm{MN}$, but at higher concentrations than were required to neutralize IIIB (Fig. $2 d$ ). It did not, however, enhance infection of either the IIIB or the MN strains.

Distinct epitopes on gp120 detected by the neutralizing $H M A b$ and the enhancing HMAb. These two HMAbs both belong to the same subclass, IgG1, which can bind to FcR I, II, and III when forming immune complexes; therefore, their different characteristics must depend on the specific interaction of the paratopes of the antibodies with determinants on the virus. The enhancing antibody N70-2.3a must react with a different epitope of gp1 20 than that which reacts with N70-1.5e. Results of ELISA showed that HMAb N70-1.5e recognizes a conformational epitope on gp 120 and its binding to gp 120 is inhibited by rCD4, as previously reported by Ho et al. (12), while HMAb N70-2.3a does not (data not shown). Also, as shown in Table II, a competition radioimmunoassay demonstrated that the binding of radioiodinated HMAb N70-2.3a was inhibited by unlabeled N70-2.3a, but not by N70-1.5e. These data indicate that the two antibodies bind to distinct epitopes.

Effect of the enhancing HMAb combined with the neutralizing $H M A b$. We examined the effect of mixing the enhancing $\mathrm{HMAb}$ and the neutralizing HMAb together on enhancement of infection to correspond to an in vivo situation (Fig. 3). HIV1 infection was significantly enhanced by the presence of monoclonal antibody N70-2.3a at $17.5 \mu \mathrm{g} / \mathrm{ml} \times 10^{-6}$ (the enhancement index was 1.49), as compared with the absence of the antibody $(P<0.01)$. On the other hand, infection was significantly reduced by the addition of the same amount of the monoclonal antibody N70-1.5e to the monoclonal antibody N70-2.3a, resulting in neutralization at dilution $10^{-1}(P<0.01)$ and inhibition of enhancement at dilution $10^{-6}$.

Identification of the epitope recognized by the enhancing $H M A b$. We used recombinant HIV-1 gp 120 polypeptides in ELISA (15) to localize the epitope for the enhancing HMAb N70-2.3a because this antibody failed to bind to gp120 under reducing conditions (data not presented). As shown in Fig. 4, N70-2.3a binds to full-length env 2-3 (denatured, nonglycosylated gp 120) but not to the amino-terminal half of gp1 20 env 1. 

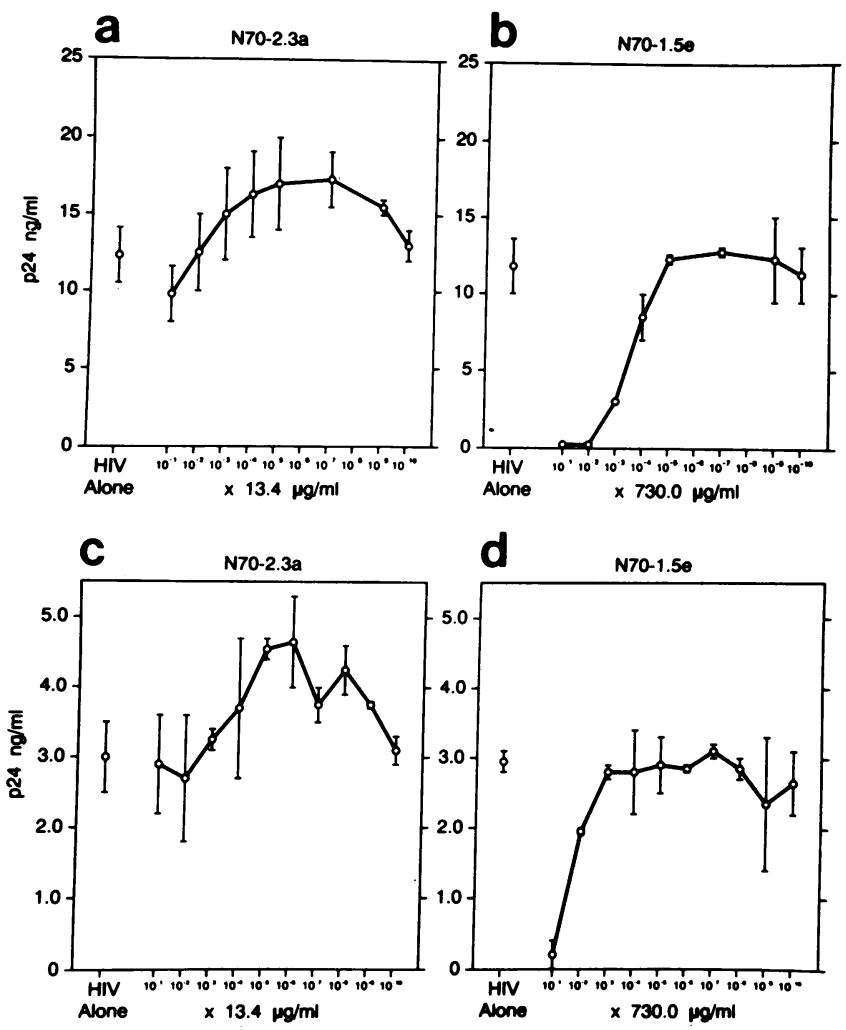

Figure 2. HIV-1 infection enhancement activities of human monoclonal antibodies N70-2.3a $(a)$ and N70-1.5e (b). Infection enhancement assays were performed with HTLV-IIIB and U937 cells as described in Methods. The protein A column-purified IgG monoclonal antibodies were serially diluted in phosphate-buffered saline at $10^{-1}$ through $10^{-10}$. A diluted sample $(900 \mu \mathrm{l})$ was mixed with an HIV-1 inoculum $\left(100 \mu 1,5 \times 10^{3} \mathrm{TCID}_{50}\right)$ and incubated for $30 \mathrm{~min}$ at $4^{\circ} \mathrm{C}$. A half million U937 cells were incubated with these mixtures, washed, and then incubated as described above. Culture supernatants were harvested on day 5 for determination of p24 content. The concentrations of the monoclonal antibodies were measured by nephelometry by the use of antibodies to IgG Fc (Beckman Instruments, Inc., Brea, CA). Sample antibodies N70-2.3a and N70-1.5e contain 13.4 and $730.0 \mu \mathrm{g} / \mathrm{ml}$, respectively. Shown is a representative experiment of three performed. Results are expressed as the mean \pm SD of duplicate cultures. HIV-1 infection enhancement activities of human monoclonal antibodies N70-2.3a $(c)$ and N70-1.5e $(d)$ with a HIV strain MN. Infection enhancement assays were performed with HTLV-IIIMN and U937 cells as described above.

The antibody is also reactive with the carboxyl-terminal half of gp120 env 4 or env 4D3, irrespective of V3 region. As the antibody also binds to env $2-3 \mathrm{D} 3$ as well as env $2-3 \mathrm{D}(16)$, the

Table II. Competition Radioimmunoassay of Human Monoclonal Antibodies (HMAbs) to HIV-1 gp120

\begin{tabular}{|c|c|c|c|}
\hline HIV-1 & Unlabeled & ${ }^{125}$ I-labeled & \\
\hline glycoprotein & HMAb & HMAb & Counts bound \\
\hline & & & $c p m$ \\
\hline+ & - & N70-2.3a & 3330 \\
\hline+ & N70-1.5e & N70-2.3a & 3060 \\
\hline+ & N70-2.3a & N70-2.3a & 1133 \\
\hline- & - & N70-2.3a & 920 \\
\hline
\end{tabular}

epitope for the enhancing antibody N70-2.3a is located within the conserved sequences between amino acid residues 272 and 509 of gp120. Similar results were obtained using a spot blot procedure (data not shown).

Comparable affinity of HMAbs. As shown in Fig. 5, binding of N70-2.3a to solid phase gp120 was almost completely blocked at all concentrations of rgp 120, while no concentration of rgp120 used was able to block binding of N70-1.5e. These data therefore indicate that the relative affinity of $\mathrm{N} 70-1.5 \mathrm{e}$ is low in comparison with the affinity of N70-2.3a.

\section{Discussion}

Antibody-dependent enhancement of HIV-1 infection is mediated by complement receptors (1) or by FcRs for IgG (3). A previous study has shown that an enhancing epitope that mediates complement receptor-dependent enhancement of infection is present at AA586-620 within gp41 of HIV-1 (19). However, the epitope(s) that induce antibodies mediating FcR-dependent enhancement of HIV-1 infection have not been defined, and it is not known if enhancing epitopes are located on gp120. Furthermore, a major question concerning whether enhancing antibodies and neutralizing antibodies can be distinguished has not been previously addressed.

In the present study, we attempted to characterize enhancing antibodies involved in FcR-mediated enhancement of HIV-1 infection by using human monoclonal antibodies reactive against the gp120 of HIV-1. The results indicate that enhancing and neutralizing antibodies can be induced by different epitopes on gp120.

The relative concentrations of antibody molecules and virions required to demonstrate neutralization by HMAb N70$1.5 e$ and enhancement by $\mathrm{N70-2.3a}$ raises some questions. Enhancement of HIV-1 infection by the antibody N70-2.3a occurs at very low concentrations of antibody, or in antigen excess when the number of virions may be greater than the

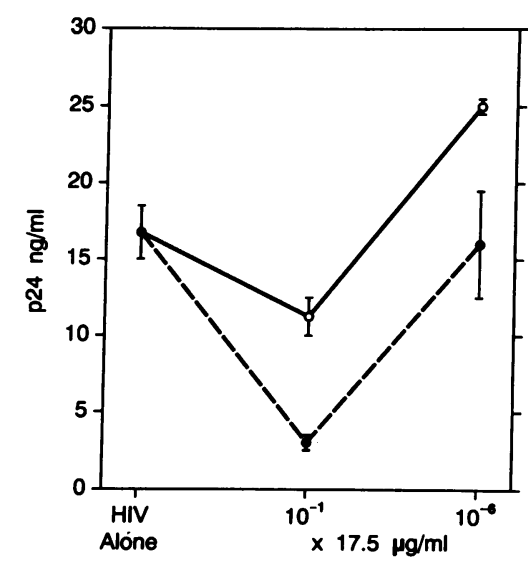

Figure 3. Effect of mixing enhancing monoclonal antibody N702.3a and neutralizing monoclonal antibody $\mathrm{N} 70-1.5 \mathrm{e}$ on infection enhancement. Assays were performed with HTLVIIIB and U937 cells as described in Methods. The protein A column-purified IgG monoclonal antibodies were used. The concentrations of the antibodies were measured by nephelometry. Enhancing monoclonal antibody N70-2.3a $(17.5 \mu \mathrm{g} / \mathrm{ml})$ alone (o) or a mixture of the antibody N70-2.3a $(17.5 \mu \mathrm{g} / \mathrm{ml})$ and the same amount of neutralizing antibody $\mathrm{N} 70-1.5 \mathrm{e}(17.5 \mu \mathrm{g} / \mathrm{ml})(\bullet)$ were diluted in phosphate-buffered saline at $10^{-1}$ and $10^{-6}$, respectively. A diluted sample $(0.9 \mathrm{ml})$ was mixed with an $\mathrm{HIV}-1$ inoculum $\left(0.1 \mathrm{ml}, 5 \times 10^{3}\right.$ $\mathrm{TCID}_{s_{0}}$ ), and incubated for $30 \mathrm{~min}$ at $4^{\circ} \mathrm{C}$. A half million U937 cells were infected with these mixtures as described above. Culture supernatants were harvested on day 5 for determination of p24 content. Results are expressed as the mean \pm SD of duplicate cultures. 
N70-2.3a
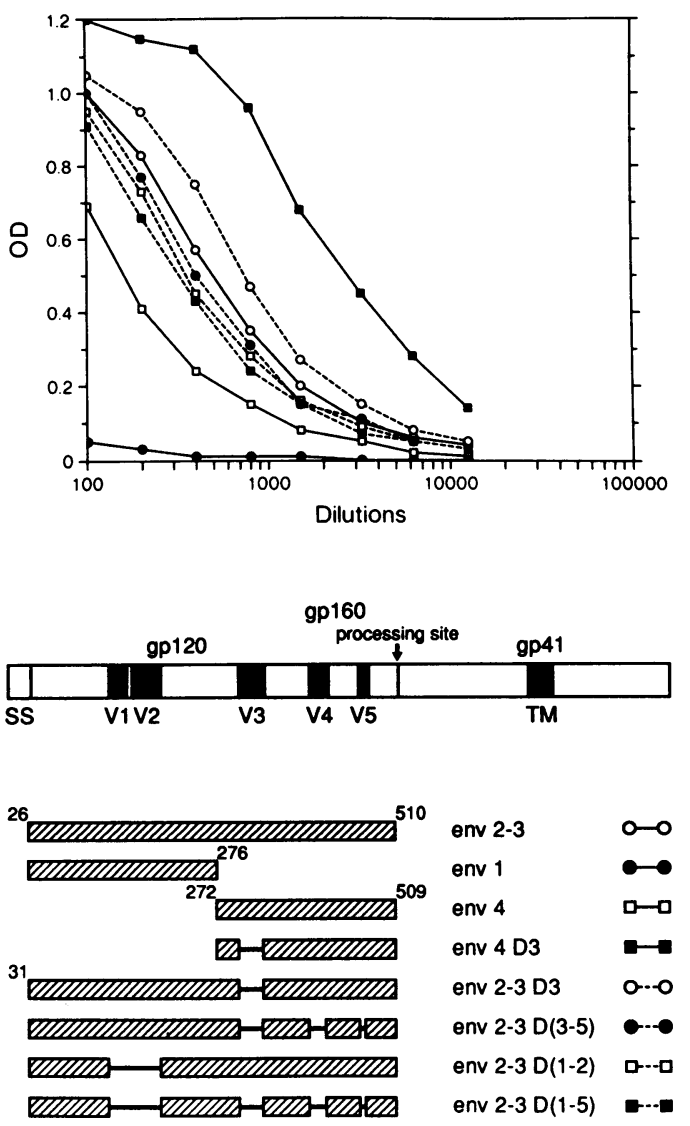

Figure 4. Reactivity of HMAb N70-2.3a to various envelope polypeptides. Nonglycosylated. HIV-1 (SF2) recombinant gp1 20 polypeptides which are illustrated on the bottom were used. Schematic diagram of the HIV-1 envelope gene showing locations of hypervariable regions and variants produced in yeast. Constant domains are shown in white and variable sequences in black. SS, signal sequence; TM, transmembrane domain. The bars shown below the diagram delineate the regions that were expressed in variants of gp 120 in yeast, and deleted regions are shown with thin connecting lines. Deletion variants were named to correspond with the variable regions deleted. Polypeptides were absorbed onto microtiter plates. Biotinylated HMAb N70-2.3a which was diluted serially was added and detected by ELISA. The optic density represents the relative amounts of HMAb N70-2.3a bound to polypeptides.

number of antibody molecules. On the other hand, for neutralizing antibody N70-1.5e we find that neutralization requires much higher concentrations of antibody (antibody excess). The quantitation of HIV-1 may vary in different HIV-1 pools. We did, however, obtain similar results in repeated experiments

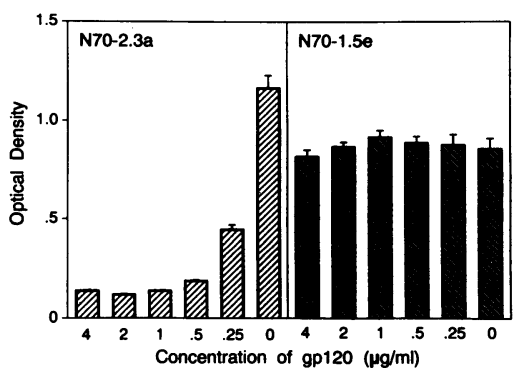

Figure 5. Comparison of relative affinities of HMAbs 2.3a and 1.5e to gp120. Assays are performed as described in Methods. Results are expressed as means of triplicate determination; error bars indicate standard deviations. which indicates that large differences in virus-antibody ratios are required for neutralizing versus enhancing activity of these monoclonal antibodies to be detected. It is of interest that antibody $\mathrm{N} 70-1.5 \mathrm{e}$ did not enhance infection even at higher ratios of virus to antibody. The neutralizing antibody N70-1.5e, which has the same Fc portion as antibody N70-2.3a, may also help the virus bind to the cell surface via its attachment with FcRs similar to enhancing antibodies. We presume, therefore, that this antibody may inhibit HIV-1 infection at a level of the infection process by blocking a site on gp 120 involved in CD4 binding (12). We have recently found convincing evidence that the CD4 molecule is required for FcR-mediated enhancement of HIV-1 infection (20), in agreement with the results of Perno et al. (21). It is also of interest that the relative affinity of N70$2.3 \mathrm{a}$ is higher than that of $\mathrm{N70-1.5e}$. This may be the reason that very low concentrations of enhancing antibody N70-2.3a can bind virions efficiently.

We analyzed the effect of mixing the enhancing HMAb and the neutralizing HMAb together on enhancement of infection to correspond to an in vivo situation. Since these HMAbs N701.5e and N70-2.3a were produced by B cell lines derived from an HIV-1-infected individual, they are likely to represent antibodies existing in the serum. Infection was significantly reduced by the addition of the same amount of the monoclonal antibody N70-1.5e to the monoclonal antibody N70-2.3a, resulting in inhibition of enhancement. These limited results need to be extended, but they may explain why the activity of HIV-1-enhancing antibodies in human sera is detected when the neutralizing antibodies are diluted out. Probably in sera certain concentrations of neutralizing antibodies inhibit enhancement by enhancing antibodies; however, after dilution of low concentrations of neutralizing antibodies enhancing activity can be detected. This result also appears to be consistent with our interpretation of the differential functions of the two monoclonal antibodies stated above. Although the number of the virions which bind to and/or internalize into the cell may be increased by mediation of antibody-FcR interactions, this increased entry of virions into cells may be abrogated by the effect of the neutralizing HMAb N70-1.5e. In sera, if neutralizing antibodies are dominant over the enhancing antibodies, we would not see enhancing activity. Thus, we tested the serum from the same donor from whom HMAb N70-1.5e and N702.3a were derived, and found no enhancing activity in it. However, the fact that enhancement can be detected in many sera at subneutralizing concentrations indicates that neutralizing antibodies, such as HMAb N70-1.5e, may be present in lesser concentrations in vivo. Perhaps the number of enhancing epitopes on gp 120 is higher than neutralizing epitopes. HMAbs will provide invaluable tools for further study to characterize epitopes that elicit neutralizing or enhancing antibodies in infected humans.

These results have implications for the potential development of safe HIV vaccines that will induce neutralizing and not infection-enhancing antibodies. The mapping study of the epitope which is recognized by the enhancing antibody N70-2.3a indicates that the antibody binds to a conformational epitope on nonvariable sequences in the carboxyl-half (AA272-509) of gp120. This suggests that such an enhancing antibody may be induced by various strains of HIV-1 and may be present in many HIV-1-infected individuals. Extensive studies to define precisely the domains that elicit enhancing antibodies is desirable for the future design of anti-HIV vaccines. 


\section{Acknowledgments}

We thank Robert Craig for technical assistance in the production of Kp120NN and Kimberly Mann for ELISA binding studies and Robert A. Lew for statistical analysis.

This work was supported by National Institutes of Health (NIH) grant RO1-AI24750, NIH grant UO1-AI26458, DAMD-C-6279, NIH grant T32-AI07272, and NIH grant AI-24030.

\section{References}

1. Robinson, W. E., D. C. Montefiori, and W. M. Mitchell. 1988. Antibodydependent enhancement of human immunodeficiency virus type 1 infection. Lancet. i:790-794.

2. Homsy, J., M. Tateno, and J. A. Levy. 1988. Antibody-dependent enhancement of HIV infection. Lancet. i:1285-1286.

3. Takeda, A., C. U. Tuazon, and F. A. Ennis. 1988. Antibody-enhanced infection by HIV-1 via Fc receptor-mediated entry. Science (Wash. DC). 242:580-583

4. Jouault, T., F. Chapuis, R. Olivier, C. Parravicini, E. Bahraoui, and J. C. Gluckman. 1989. HIV infection of monocytic cells: role of antibody-mediated virus binding to Fc-gamma receptors. AIDS (Phila.). 3:125-133.

5. Homsy, J., M. Meyer, M. Tateno, S. Clarkson, and J. A. Levy. 1989. The Fc and not CD4 receptor mediates antibody enhancement of HIV infection in human cells. Science (Wash. DC). 244:1357-1360.

6. Matsuda, S., M. Gidlund, F. Chiodi, A. Cafaro, A. Nugren, B. Morein, K. Nilsson, E. M. Fenyo, and H. Wigzell. 1989. Enhancement of human immunodeficiency virus (HIV) replication in human monocytes by low titres of anti-HIV antibodies in vitro. Scand. J. Immunol. 30:425-434.

7. Popovic, M., M. H. Sarngadharan, F. Read, and R. C. Gallo. 1984. Detection, isolation, and continuous production of cytopathic retroviruses (HTLV-III) from patients with AIDS and pre-AIDS. Science (Wash. DC). 224:497-500.

8. Robinson, J. E., D. Holson, J. Liu, H. McMurdo, A. Murciano, and R. Gold. 1990. A novel enzyme-linked immunosorbent assay (ELISA) for the detection of antibodies on HIV-1 envelope glycoproteins based on immobilization of viral glycoproteins in microtiter wells coated with concanavalin A. J. Immunol. Methods 132:63-71.

9. Chiang, C. S., T. Grove, M. Cooper, J. Cuan, A. Kowalski, K. Parcells, M. Tsumokawa, M. Rosenberg, E. Arcuri, S. Franklin, et al. 1989. Development of a confirmatory enzyme-linked immunosorbent assay for HIV-1 antibodies. Clin. Chem. 35:946-952.

10. Shaw, G. M., B. H. Hahn, S. K. Arya, J. E. Groopman, R. C. Gallo, and F.
Wong-Staal. 1984. Molecular characterization of human T-cell leukemia (lymphotropic) virus type III in the acquire immune deficiency syndrome. Science (Wash. DC). 226:1165-1171.

11. Robinson, J. E., D. Holton, S. Pacheco-Morell, J. Lin, and H. McMurdo. 1990. Identification of conserved and variant epitopes of human immunodeficiency virus type 1 (HIV-1) gp 120 by human monoclonal antibodies produced by EBV transformed cell lines. AIDS Res. Hum. Retroviruses. 6:567-579.

12. Ho, D. D., J. A. McKeating, S. Xiling, T. Moridgil, E. S. Daar, N-C. Sun, and J. E. Robinson. Conformational epitope on gp 120 important in CD4 binding and HIV-1 neutralization identified by a human monoclonal antibody. 1991. J. Virol. 65:489-493.

13. Scott, C. F., Jr., S. Silver, A. T. Profy, S. D. Putney, A. Langlois, K. Weinhold, and J. F. Robinson. 1990. Human monoclonal antibody that recognizes the V3 region of human immunodeficiency virus $\mathrm{gp} 120$ and neutralizes the human T lymphotropic virus type III MN strain. Proc. Natl. Acad. Sci. USA. 87:8597-8601.

14. McDougal, J. S., S. P. Cort, M. S. Kennedy, C. D. Cabridilla, P. M. Feorino, D. P. Francis, D. Hicks, V. S. Kalyanamraman, and L. S. Martin. 1985. Immunoassay for the detection and quantitation of infectious human retrovirus, lymphoadenopathy-associated virus (LAV). J. Immunol. Methods. 76:171-183.

15. Ho, D. D., J. C. Kaplan, I. E. Rackanskas, and M. E. Gurney. 1988. Second conserved domain of gp 120 is important for HIV infectivity and antibody neutralization. Science (Wash. DC). 239:1021-1023.

16. Haigwood, N. L., J. R. Shusten, G. K. Moore, H. Lee, P. V. Skiles, K. W. Higgins, P. J. Barr, C. George-Nasciminto, and K. S. Steimer. 1990. Importance of hypervariable regions of HIV-1 gp120 in the generation of virus neutralizing antibodies. AIDS Res. Hum. Retroviruses. 6:855-869.

17. Levy, J. A., A. D. Hoffman, S. M. Kramer, J. F. Landis, J. M. Shimiabukuro, and L. S. Oshire. 1984. Isolation of lymphocytopathic retrovirus from San Francisco patients with AIDS. Science (Wash. DC). 225:840-847.

18. Friguet, B., A. F. Chaffotte, L. Djavadi-Ohaniance, and M. E. Goldberg 1985. Measurements of the true affinity constant in solution of antigen-antibody complexes by enzyme-linked immunosorbent assay. J. Immunol. Methods. 77:305-319.

19. Robinson, W. E., Jr., T. Kawamura, D. Lake, Y. Masuho, W. M. Mitchell, and E. M. Hersh. 1990. Antibodies to the primary immunodominant domain of human immunodeficiency virus type 1 (HIV-1) glycoprotein gp4l enhance HIV1 infection in vitro. J. Virol. 64:5301-5305.

20. Takeda, A., R. W. Sweet, and F. A. Ennis. 1990. Two receptors are required for antibody-dependent enhancement of human immunodeficiency virus type 1 infection: CD4 and Fc R. J. Virol. 64:5605-5610.

21. Perno, C. F., M. W. Baseler, S. Broder, and R. Yarchoan. 1990. Infection of monocytes by human immunodeficiency virus type I blocked by inhibitors of CD4-gp 120 binding, even in the presence of enhancing antibodies. J. Exp. Med. 171:1043-1056. 